\title{
Oncocytic Carcinoma Ex Pleomorphic Adenoma
}

\author{
Demet Etit - Ayca Tan - Umit Bayol - Deniz Altinel · \\ Suheyla Cumurcu $\cdot$ Ibrahim Cukurova
}

Received: 2 September 2009/ Accepted: 29 November 2009/Published online: 10 December 2009

(c) Humana 2009

\section{Introduction}

Carcinoma ex pleomorphic adenoma (CaexPA) is a carcinoma that shows histologic evidence of arising in a pleomorphic adenoma. The diagnosis is made on identification of benign tumor or carcinoma arising in a site previously involved by pleomorphic adenoma. Most often the carcinomatous element is adenocarcinoma, not otherwise specified (NOS), but occasionally a specific histologic type, such as salivary duct carcinoma, mucoepidermoid carcinoma, adenoid cystic carcinoma can be identified [1-5].

Onococytic carcinoma (OC) is a rare, predominantly oncocytic neoplasm. The terms OC and oncocytic adenocarcinoma are synonymous. Malignant oncocytic tumors can occur in many organs such as thyroid, kidney, ovary, nasal cavity etc. as well as in salivary glands. The oncocytic nature of the tumor cells is confirmed with special methods, such as histochemical or immunohistochemical stains [2]. OC's rarity is highlighted by the absence of this tumor in many large salivary gland neoplasm series [4, 6-11].

Here we present the first reported case of CaexPA with purely oncocytic carcinomatous elements.

D. Etit · A. Tan $(\bowtie) \cdot$ U. Bayol $\cdot$ D. Altinel $\cdot$ S. Cumurcu Department of Pathology, Tepecik Research and Training Hospital, 2040 Sok. Pamukkale 6. Blok 102 Giris Daire: 3 Mavisehir, 35540 Izmir, Turkey

e-mail: aycaozkan9979@gmail.com

I. Cukurova

Otolaryngology, Head and Neck Surgery, Tepecik Research and Training Hospital, Izmir, Turkey

\section{Case Report}

A 53-year-old male present with a chief complaint of a 5 month history of rapid growth of a right parotid gland mass that had been stable for 20 years. Magnetic resonance imaging revealed a $6 \mathrm{~cm}$ lesion of the right parotid gland with pathologic lymph nodes in the ipsilateral cervical region.

A total parotidectomy with a functional neck dissection was performed. Macroscopically, two distinct tumors were identified, one located in the superficial lobe with a diameter of $5.5 \mathrm{~cm}$ and the other located in the deep lobe with a diameter of $3.5 \mathrm{~cm}$. On cut surface both lesions were firm, yellow in color with a nodular-infiltrative growth pattern. In the deep lobe, the mass had some fleshy, myxoid areas.

Microscopically the tumor in the superficial lobe exhibited a tumor composed of large, round, polyhedral cells arranged in small clusters, with isolated individual cells, and occasionally, solid sheets. On hematoxylin and eosin (H\&E) slides, cells had abundant, finely granular, eosinophilic cytoplasm. Many of the oncocytic cells had pleomorphic, medium or large nuclei with an eosinophilic irregular, macronucleoli (Figs. 1, 2). Necrosis and extensive lymphovascular tumoral thrombi were noted, but no comedonecrosis, tubular, cribriform or papillary areas were seen (Fig. 2). Focally, oncocytic changes were noted in residual normal salivary gland parenchyma. In the deep lobe, in addition to the neoplastic oncocytes, there was close association of various epithelial cell types some forming ductal structures and myxoid mesenchymal-like stroma of a typical pleomorphic adenoma (Fig. 3). The oncocytic cells stained dark blue with PTAH (Fig. 4). Tumor showed no immunoreactivity for S-100, HMB-45, Vimentin, CK-20, and SMA. The tumor showed positive 


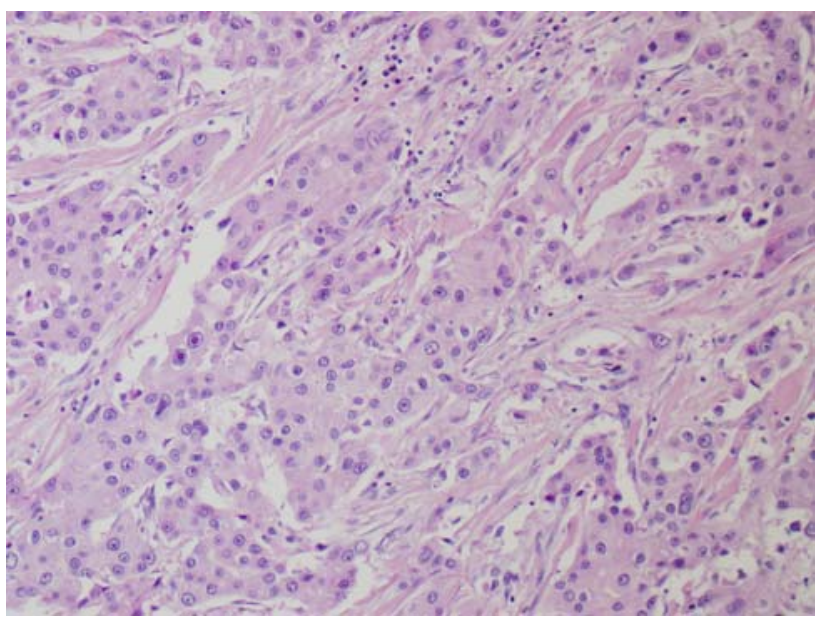

Fig. 1 Individual and clusters of cells with abundant pink cytoplasm $(\mathrm{H} \& \mathrm{E} \times 20)$

immunoreactivity for AE-1/AE-3, CK-7, CEA, EMA and p63 (Fig. 5). No cytoplasmic staining for PAS, PAS-D or mucicarmine stains were seen in the oncocytic cells. All 23 dissected cervical lymph nodes were positive for metastatic tumor. The largest node measured $2.8 \mathrm{~cm}$ with extracapsular extension into the perinodal soft tissue.

\section{Discussion}

CaexPA constitutes $12 \%$ of malignant salivary gland tumors. It usually presents in the 6th or 7 th decades and most frequently arises in the parotid gland with female predilection [5, 12-14]. Our patient was a 53-year-old male with a right parotid gland tumor.

To satisfy the definition of CaexPA, at least a focus of benign pleomorphic adenoma must be identified or a previous benign pleomorphic adenoma must have been excised from a site in which recurrent tumor is carcinomatous. In our case $50 \%$ of the tumor in the deep lobe was histologically compatible with pleomorphic adenoma with oncocytic carcinoma, while $100 \%$ of the tumor in the superficial lobe was oncocytic carcinoma.

Many types of benign and malignant salivary gland tumors can have foci of oncocytic cells. If the oncocytic component comprises a small portion of the lesion the differential diagnosis is not a challenge. Oncocytomas may be unencapsulated and exhibit atypical nuclear changes which may make a distinction from oncocytic carcinoma complicated. In comparison with those two entities oncocytic carcinomas usually have considerably greater mitotic figures, cellular pleomorphism and most importantly unequivocal evidence infiltration into surrounding tissues. The current case showed a tumor composed exclusively of malignant oncocytic cells with extensive infiltration into the surrounding tissues including muscle, vascular and perineural invasion with 23 metastatic cervical lymph nodes.

Salivary gland tumors composed of large cells with abundant granular cytoplasm include acinic cell carcinoma (ACC) and salivary duct carcinoma (SDC). The granules in the tumor cells of ACC are usually amphophilic or
Fig. 2 a Tumoral thrombi within erythrocytes filled vascular spaces $(H \& E \times 40)$. b The tumor cells with large, round or polygonal cytoplasm arranged in small clusters with individual cells $(\mathrm{H} \& \mathrm{E} \times 20)$. c-d Cells with abundant granular cytoplasm with prominent eosinophilic nucleoli $(\mathrm{H} \& \mathrm{E} \times 40)$

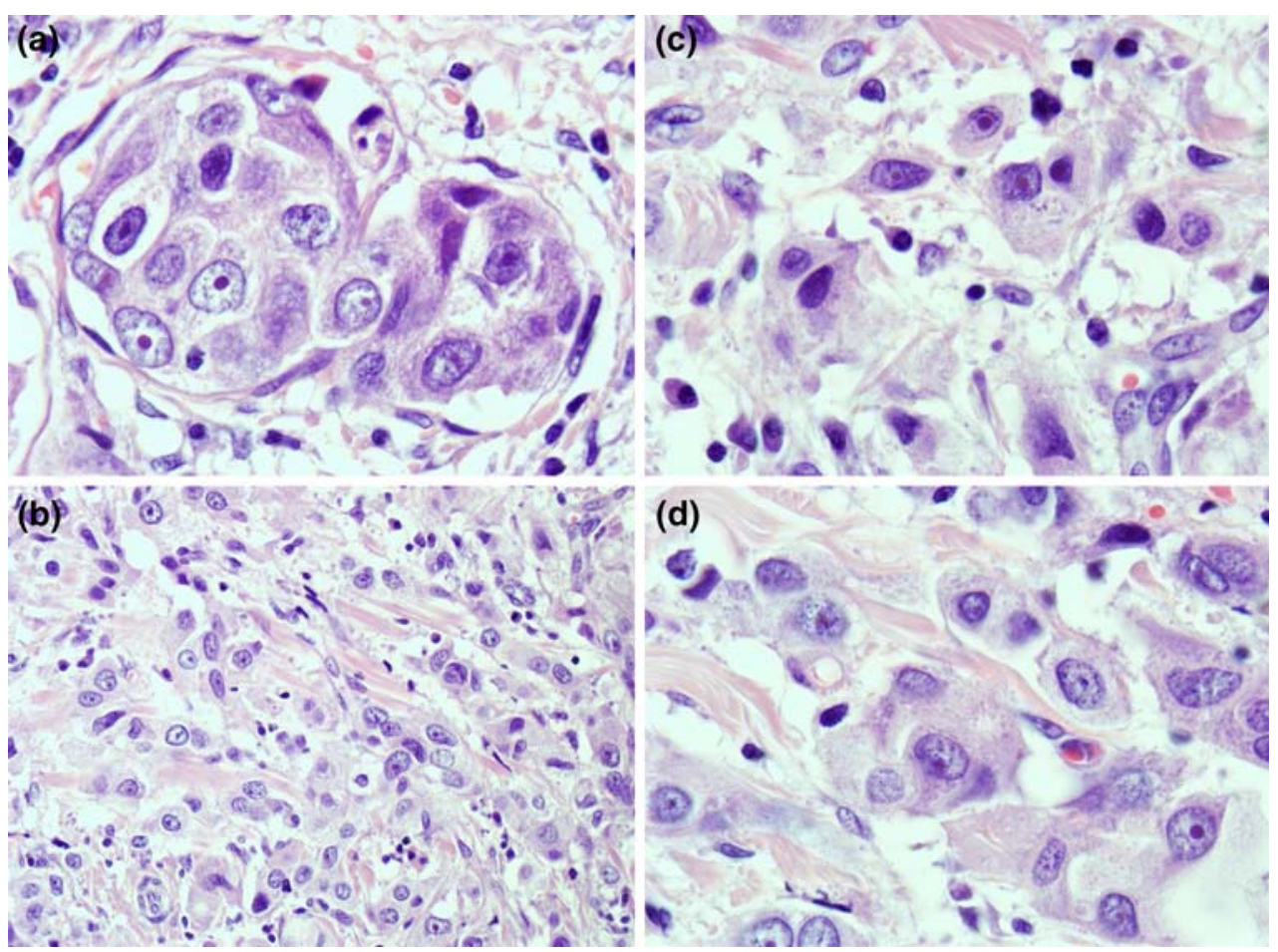


Fig. 3 The pleomorphic adenoma $(P A)$ with myxoid background and ductal epithelial structures $(\mathrm{H} \& \mathrm{E} \times 10)$
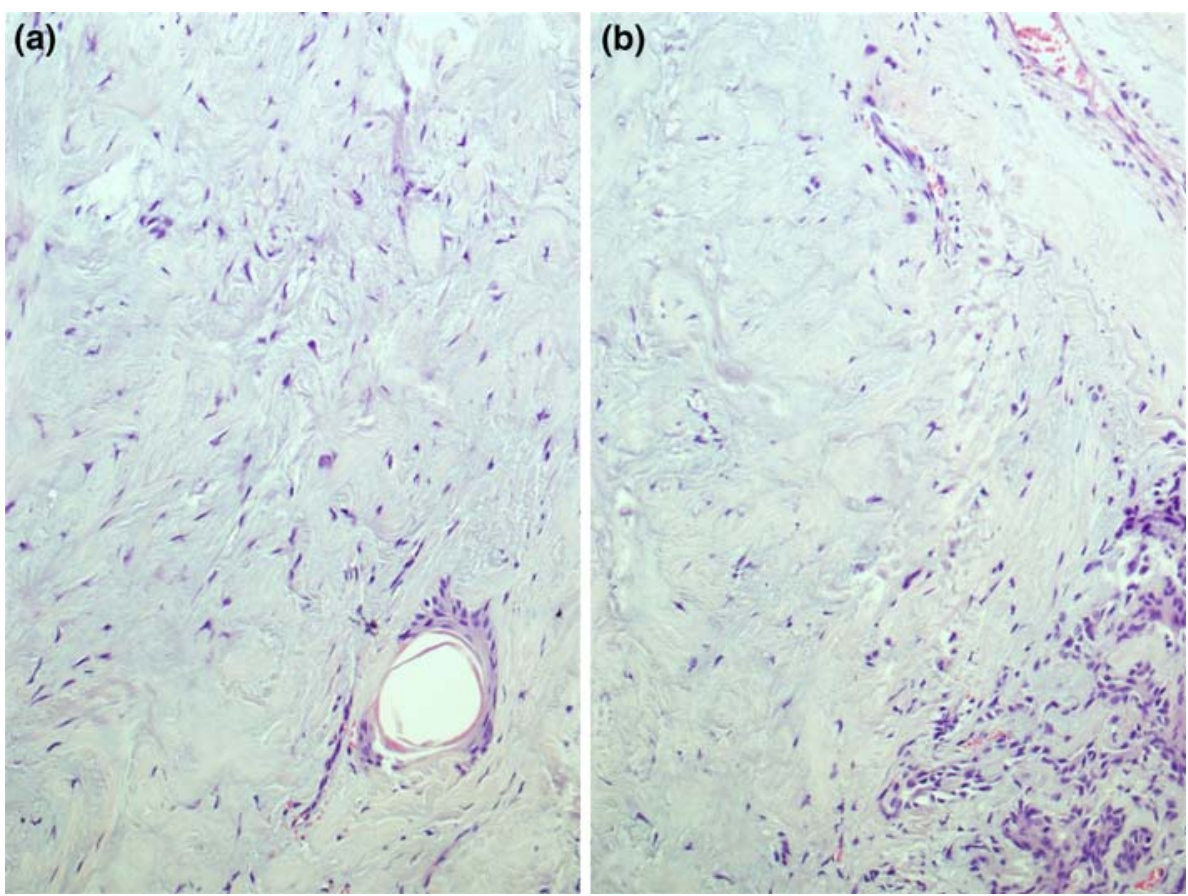

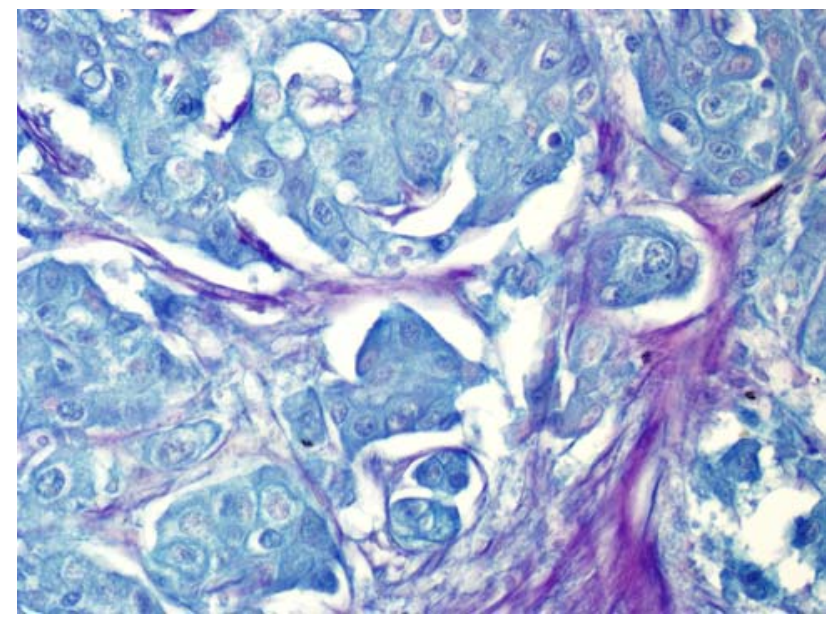

Fig. 4 The cytoplasm stain dark blue and the granularity is emphasized by PTAH $(\times 40)$

basophilic and are PAS positive before and after diastase digestive. In SDC the tumor cells form cysts and duct-like spaces with papillary and cribriform growth, and often comedonecrosis. Either SDC or ACC are unreactive with PTAH $[15,16]$. Also included in the differential diagnosis was renal cell carcinoma metastasis but this was ruled out with vimentin negativity and p63 positivity. In addition computed tomography of the kidneys did not show abnormalities.

In conclusion, a rare case of CaexPA in the parotid gland was reported. The malignant component was OC, which is

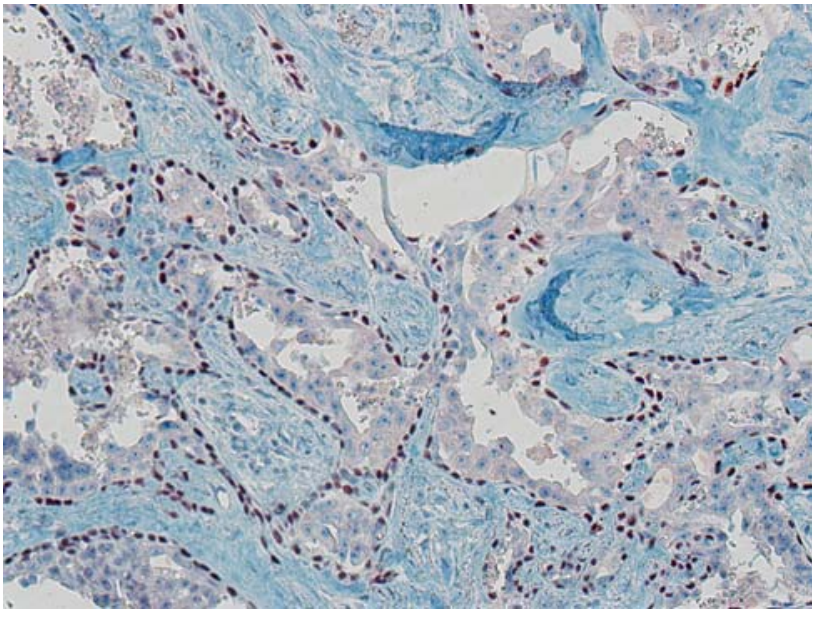

Fig. 5 The peripheral staining of the tumor nests in the nuclei of the cells with p63 $(\times 20)$

the first reported case in the English language literature to our knowledge. Despite the rarity of OC, evidence supports high-grade biologic behaviour. In the largest reported series patients had recurrences and distant metastases. Cervical lymph node metastases are frequently seen as evidenced in our case that had 23 postive lymph nodes with perinodal capsular and soft tissue invasion [15-17].

The clinical significance of $\mathrm{OC}$ to the prognosis of CexPA has not known. After surgery and adjuvant radiochemotherapy in 5 month follow-up period, there is no evidence of disease in our patient. 


\section{References}

1. Cohn ML, Callender DL, El-Naggar AK. Sebaceous carcinoma ex-pleomorphic adenoma: a rare phenotypic occurrence. Ann Diagn Pathol. 2004;8:224-6.

2. Ellis GL, Auclair PL. Malign epithelial neoplasms. In: Tumors of the salivary glands. Armed Forces Institute of Pathology; 2008. p. $173-439$.

3. Jacobs JC. Low grade mucoepidermoid carcinoma ex pleomorphic adenoma. A diagnostic problem in fine needle aspiration biopsy. Acta Cytol. 1994;38:93-7.

4. Olsen KD, Lewis JE. Carcinoma ex pleomorphic adenoma: a clinicopathologic review. Head Neck. 2001;23:705-12.

5. Tortoledo ME, Luna MA, Batsakis JG. Carcinomas ex pleomorphic adenoma and malignant mixed tumors. Histomorphologic indexes. Arch Otolaryngol. 1984;110:172-6.

6. Lewis JE, Olsen KD, Sebo TJ. Carcinoma ex pleomorphic adenoma: pathologic analysis of 73 cases. Hum Pathol. 2001;32: 596-604.

7. Yu GY, Ma DQ. Carcinoma of the salivary gland: a clinicopathologic study of 405 cases. Semin Surg Oncol. 1987;3:240-4.

8. Seifert G, Miehlke A, Haubrich J, et al. Diseases of the salivary glands: pathology, diagnosis, treatment, facial nerve surgery. Stuttgart: Georg Thieme; 1986.

9. Woods JE, Chong GC, Beahrs OH. Experience with 1, 360 primary parotid tumors. Am J Surg. 1975;130:460-2.
10. Eveson JW, Cawson RA. Salivary gland tumours. A review of 2410 cases with particular reference to histological types, site, age and sex distribution. J Pathol. 1985;146:51-8.

11. Spiro RH. Salivary neoplasms: overview of a 35 -year experience with 2, 807 patients. Head Neck Surg. 1986;8:177-84.

12. Gnepp D, Brandwein-Gensler M, El-Naggar A, et al. Carcinoma ex pleomorphic adenoma. In: Barnes L, Eveson J, Reichart P, Sidransky D, editors. Pathology and genetics of head and neck tumours. Lyon: IARC Press; 2005. p. 242-43.

13. Spiro RH, Huvos AG, Strong EW. Malignant mixed tumor of salivary origin: a clinicopathologic study of 146 cases. Cancer. 1977;39:388-96.

14. LiVolsi VA, Perzin KH. Malignant mixed tumors arising in salivary glands. I. Carcinomas arising in benign mixed tumors: a clinicopathologic study. Cancer. 1977;39:2209-30.

15. Delgado R, Vuitch F, Albores-Saavedra J. Salivary duct carcinoma. Cancer. 1993;72:1503-12.

16. Hui KK, Batsakis JG, Luna MA, et al. Salivary duct adenocarcinoma: a high grade malignancy. J Laryngol Otol. 1986;100: 105-14.

17. Gray SR, Cornog JL Jr, Seo IS. Oncocytic neoplasms of salivary glands: a report of fifteen cases including two malignant oncocytomas. Cancer. 1976;38:1306-17. 